justice to be done to the ever-increasing pace and volume of advancing knowledge. The first edition, once read, remained on the bookshelf, an imposing volume, but at that time the trends were only being born, now they are lively youngsters, pressing in all directions.

Non-invasive cervical carcinoma, which is well described, poses not only questions of definition and diagnosis, but also sets fresh administrative and financial problems for the clinico-pathological gynæcological service, if the maximum number of early diagnoses are to be made and the incidence of the tragic advanced carcinoma is to be decreased.

The rare chorion epithelioma introduces the importance of immunological reactions, yet unrecognized in pregnancy. So far only the blood group factors have been studied. The chemotherapy of this most fatal condition is arrestingly discussed and begins to remove the complete hopelessness we have all felt, particularly when apparently the condition followed an earlier normal confinement.

The chapter on stress incontinence of urine is stimulating and informative, as would be expected from the authorship. The need for time for detailed patient study is amply demonstrated.

The problem of the incompetent cervix is less that of technique than of indication and timing.

Urinary tract infections are assuming much greater importance, as the increasing incidence, difficulties in diagnosis and fatalities are put into focus. This chapter should be read, a 'ban-the-catheter' campaign considered, and other causal factors studied.

The three chapters on biochemistry are most readable and of great importance. The trends covered in the book are too many to review in detail, and I am left pondering on the importance which many have suspected, and the ingenious method of investigation, of the fœto-placental unit.

\section{Physiology of the Circulation in Human Limbs in Health and Disease}

John T. ShePherd, M.D., M.CH., D.sC. Pp. ix + 4I6 with 179 illustrations. Philadelphia \& London: W. B. Saunders. 1963. 84s.

The author of this book is well known in this country as a former member of the team which, under Professor A. D. M. Greenfield, has done so much excellent work on the peripheral circulation. As Dr. Shepherd points out, much information concerning the circulation in human limbs, with its ramifications in the cardiovascular system as a whole, has accumulated during the past ten years. His book provides a welcome and timely survey of this increasingly complex field.

An attempt has been made to analyse and correlate the large amount of data now available, and for this purpose the material is well presented. After a very brief outline of the methods used in studying the circulation, the book is divided into four sections in terms of the main factors affecting blood vessels. The first three sections cover in turn the nervous, local and humoral control of blood vessels, while the final section describes the modification of blood vessel activity by disease. The various aspects of each subject are discussed in separate chapters within the main sections, and a full and up-to-date list of references is given at the end of each chapter. The relatively new areas in circulatory physiology such as the evidence for receptors in low-pressure zones of the intrathoracic vascular bed concerned with the regulation of muscle blood flow, the response of blood vessels to changes of transmural pressure, and the vascular effects of such substances as 5-hydroxy-tryptamine and bradykinin are well documented. On the clinical side, the circulatory changes in a wide range of conditions from Raynaud's disease to osteitis deformans are described.

Dr. Shepherd has aimed at a large audience includiog the graduate student, the serious investigator and the clinician concerned with diseases affecting the vascular system. He has succeeded to a large extent and gีl types of readers will find useful information lucidfy presented.

The book is well illustrated with numerous grapl It is generally free of serious printing errors (except far an unfortunate chapter heading of idiopathic orthestatic hypertension), and the cost is not prohibitive. By bringing together information on its various aspects, Dr. Shepherd has in this book made a definite contrib世 tion towards the understanding of the human circulatiof in health and disease.

\section{A Textbook of Surgical Pathology}

Sir Charles Illingworth and Bruce M. Diç 9 th edition. Pp. viii +696 , with 336 illustrations: London: J. \& A. Churchill. 1963. 90s.

The appearance of the ninth edition of Illingworth and Dick's Textbook of Surgical Pathology, within three years of the last edition, testifies to the popularity of this book. It is widely read by those preparing fot the Final Fellowship examinations, for whom it provides a well-orientated, up-to-date, survey of surgical aspegss of pathology.

The illustrations and microphotographs, many of which are new, conform to the high standard that his been a feature of previous editions. The provision of references to original papers and reviews was discontinued with the last edition. However, there p@ss throughout the text names of workers, some at Rast, unfamiliar to the reader and serving no useful purise in the absence of any reference to their publications.

The authors devote a chapter to transplantation a preservation of tissues, but, although they state in the preface to this edition that the section on the homogralt reaction has been expanded, in fact this chapter क्षेs identical to that in the eighth edition. This seemsa pity as the field of homotransplantation is of considerabe current interest to pathologist and surgeon alike, and rapid strides have been made during the past two or three years.

These are, however, minor criticisms of an excellent textbook.

\section{Cerebral Palsy in Children and its Treatment}

M. B. Eidinova and Ye. N. Pravdina-vinarskay,

Translated from the Russian. Pp. xv + I illustrated. Oxford, London, New York and Paris: Pergamon Press. 1963. 70s.

It is inevitable we judge the work from other countrios by our own standards. I was at first reminded of Crothers \& Paine's 'Natural History of Cerebral Pals but not for very long. For although this book is bas on clinical experience there is little factual evidence $\infty$ support their glowing claims of success. Mention is made in Chapter 4 of 76 children who were studied ard treated. Age, sex distribution, educational attainment and very detailed information of ætiology is provided but "we found the qualification and classification of their motor disorders extremely complicated' so mugh so that in the almost anecdotal case reports of progress they are impressive without being ronvincing. This book reflects the new ground which is being broken in Russia in this field. The sincerity of their plea forठa hopeful and not defeatist attitude, for active carefulty thought out lines of treatment and not a passive ind 1 ference is reflected in 'the majority of doctors regasd 